\title{
An application of New Keynesian models to inflation in Croatia
}

\author{
Alan Domić \\ Faculty of Economics and Business, University of Zagreb, Zagreb, Croatia
}

\section{Abstract}

Background: The inflation dynamics of Croatia is studied in the paper, with the review of applicable marginal cost proxies for the hybrid New Keynesian Phillips Curve (NKPC), and estimation of three specifications of the hybrid NKPC for Croatia. Objectives: The goal of this research is to examine the effect of labor's share of income, the price of energy, and the price of imports and other open economy factors in driving inflation in Croatia from the first quarter of 2000 to the fourth quarter of 2011. Methods/Approach: We use the generalized method of moments (GMM) estimator to empirically estimate three NKPC specifications. The J-stat and Cragg-Donald F-test are used to test for overidentification and for weak instruments, respectively. Results: We find that the marginal cost proxy for the energy-augmented specification is statistically significant and quantitatively the largest, whereas those for the other two are statistically significant, but quantitatively negligible. Conclusions: The results provide an empirical contribution both to the literature on inflation in Croatia and the literature of the NKPC in a small open economy. We can conclude that the price of energy has been the strongest driver of inflation, whereas the open economy factors we tested have had very little influence.

Keywords: New Keynesian Phillips curve, inflation, open economy, Croatia, real marginal cost, GMM. JEL Classification: C01, C13, E31, E37

Paper type: Research article

Recieved: 29, November, 2011

Revised: 11, July, 2012

Accepted: 20, July, 2012

Citation: Domić, A. (2012). "An application of New Keynesian models to inflation in Croatia", Business Systems Research, Vol. 3, No. 2, pp. 6-13.

DOI: 10.2478/v10305-012-0008-y

Acknowledgments: I would like to acknowledge the kind and patient support of my mentor, professor Ksenija Dumičić, without whom this work would not have been possible.

\section{Introduction}

The modelling of inflation in the short run is an area of macroeconomics where answers are both urgently needed yet difficult to obtain. They are urgently needed because accurate forecasts of short-run inflation are vital for effective monetary policy; however, there are as yet no forecast methods that perform equally reliably in all situations. Phillips curve forecasts (in their current form, i.e. those forecasts that rely on a real activity variable such as unemployment, the output gap, or real marginal costs) appear to achieve better results than any other currently used method (Stock and Watson, 2008).

The New Keynesian Phillips Curve (NKPC) has been the focus of a great deal of recent research in inflation forecasting, and (consequently, to some degree) it is now a part of the monetary policy toolset for many countries. Having evolved from A.W. Phillips' relation of unemployment to inflation, the NKPC, in the form it takes today, relates a real activity such as the output gap or real marginal cost to inflation. That real activity variable is arguably the most disputed and most actively researched aspect of the NKPC, and the definitive form of the relation is far from being a settled issue.

This study's aim is to contribute to the literature by examining the causes of inflation in Croatia and by estimating the NKPC for a small open economy with corrected measures of marginal cost; most empirical NKPC studies have been carried out for large and highly developed countries, using the labor share 
of income as a proxy for marginal cost, which has shown to be problematic (Wolman, 1999, Rudd and Whelan 2005, 2007). It is particularly problematic for a small open economy, and several approaches have been developed in response, most notably those by Leith and Malley (2003) and Dabušinskas and Kulikov (2007). We empirically test these approaches, and also review other promising approaches that could not be adapted for modeling the case of Croatia, with a discussion of what makes them an approach worth considering and what is problematic in adapting them to the Croatian economy.

First, we describe our specifications of the NKPC and briefly discuss the issues surrounding proxies of real marginal cost. Second, we describe our data set and methodology. Third, we present our results using the generalized method of moments (GMM) estimator. Fourth, we discuss alternative approaches to adjusted marginal cost that are promising but could not be adapted for the purposes of this study, and we conclude with a review of the study and a discussion of the possible directions of future research.

\section{Theoretical Framework}

To estimate the NKPC for a given economy, a model of price setting in that economy is necessary. In this paper, we will use the model of price adjustment introduced by Calvo (1983), the most widely used model in the NKPC literature.

This model assumes an economy with monopolistically competitive firms that are perfectly identical, except for the differentiated products they produce, and for their pricing history. Each identical firm faces the same constant price elasticity of demand for its differentiated product. Some firms, whose proportion is given by $(1-\theta)$, adjust prices in period t, and that probability is independent of the firm's pricing history up to period t. The pricing decisions are formulated as a monopolistic competitor's profit maximization problem, given a stream of expected future marginal costs and given the ability to set a frictionless optimal markup over marginal costs. For the sake of simplicity and brevity, we only provide the closed form of the NKPC with Calvo model pricing in this paper, and not the full derivation. In addition to the original description of the pricing structure in Calvo (1983), the full derivation is available in, among others, Gali and Gertler (1999) and in Leith and Malley (2003) for an open economy model. After including a discount factor $\beta$, the NKPC is given by

$$
\pi_{t}=\beta E_{t} \pi_{t+1}+\lambda m c_{t}^{r}
$$

Where

$$
\lambda=\frac{(1-\theta)(1-\theta \beta)}{\theta}
$$

and where $\pi_{t}$ is the rate of inflation in period $t, E_{t} \pi_{t+1}$ is the expected rate of inflation of the period $t+1$ in period $t$, and $m c_{t}^{r}$ is real marginal cost in period $t$.

The NKPC can also be expressed with the output gap (the difference between real and potential output) substituted for marginal costs (Galí, 2002). But this choice is becoming increasingly deprecated, primarily because in empirical data the output gap leads inflation for a given period, rather than the other way around as the NKPC implies; because of this, real marginal cost is typically used in the literature instead of the output gap (Mazumder, 2010).

However, accurate measurement of real marginal cost is one of the most problematic areas of NKPC research (Mazumder, 2010). We shall give an overview of this, including the measures we use to attempt to obtain a better fit for the NKPC, and we will present a longer discussion of recently proposed alternatives. We now turn to the NKPC specification that is the most widely used in the literature, and that we shall also use in this study.

Hybrid new Keynesian Phillips curve

The so-called hybrid NKPC, which incorporates a lagged inflation term, was introduced by Galí and Gertler (1999), and its specification is as follows: 


$$
\pi_{t}=\gamma_{f} E_{t} \pi_{t+1}+\gamma_{b} \pi_{t-1}+\lambda m c_{t}^{r}
$$

Where

$$
\begin{gathered}
\lambda \equiv(1-\omega)(1-\theta)(1-\beta \theta) \phi^{-1} \\
\gamma_{f} \equiv \beta \theta \phi^{-1} \\
\gamma_{b} \equiv \omega \phi^{-1} \\
\phi \equiv \theta+\omega[1-\theta(1-\beta)]
\end{gathered}
$$

In the hybrid NKPC, there is a fraction of firms, given by $1-\omega$, that behave exactly like all firms in Calvo's model. The remaining firms in the economy, given by $\omega$, set their prices using a backward-looking rule of thumb. This rule is defined by two features: (1) there are no persistent deviations between that rule and optimal behavior; and (2) the price decision for period t depends only on information from t-1 and earlier. Firms described by $\omega$ set their price according to $p_{t}^{b}=p_{t-1}^{*}+\pi_{t-1}$, where $p_{t-1}^{*}$ is the average price level set in the round of price adjustments at $t-l$ (note that, in this way, the backward-looking firm indirectly takes into account information about the future, since the average price level includes prices of forward-looking firms). When $\omega=0$, that is, when there are no backward-looking firms in the economy, the hybrid NKPC converges to the conventional NKPC form.

\section{Real marginal cost and our approach (Model (3))}

Since real marginal cost cannot be observed, a proxy must be found. Following Galí and Gertler (1999), who assumed a Cobb-Douglas production function, the choice of proxy has in recent literature overwhelmingly fallen on labor's share of income (or, equivalently, real unit labor costs). The empirical results obtained since then, from diverse data sets, have led to this choice of proxy being strongly criticized (Wolman, 1999; Rudd and Whelan 2005; 2007) on the grounds that only using labor's share of income fails to create a good fit for the NKPC. The studies cited do not go so far as to assert that the theoretical basis must be scrapped, but they strongly affirm that labor's share alone is inadequate and that, for the given specification of the NKPC, a better proxy for real marginal cost must be found.

This has provided the stimulus for a spate of research. A number of alternative measures have been proposed, the most promising of which may be those of Muto (2009) and Bratsiotis and Robinson (2009), who developed successful frameworks of labor adjustment costs, and capital and labor marginal costs, respectively; a full discussion of those frameworks is one of the subjects of following part oft he paper. However, Muto (2009) does not use GMM, only OLS and NLS.

\section{Energy-augmented hybrid new Keynesian Phillips curve (Model (5))}

Dabušinskas and Kulikov (2007), in their empirical analysis of inflation in Estonia, Latvia and Lithuania, use two different NKPC specifications that are of interest to us. The first is what they refer to as the energyaugmented Phillips curve, and which explicitly includes the price of energy in its measure of marginal cost, given by:

$$
\hat{m} c_{t}^{r}=\hat{s}_{t}-(1-\mu s)(\rho-1)\left(\hat{p}_{t}^{E}-\hat{w}_{t}\right)
$$

where $\mu$ is the markup, $p$ is a measure of the elasticity of substitution between labor and imported intermediate goods, $s$ is labor's share of income, and $\left(\hat{p}_{t}^{E}-\hat{w}_{t}\right)$ is the price of energy relative to wages. All hatted variables represent log-deviations from their steady state ( $\mu$ and $p$, of course, are constants). 
Open economy hybrid new Keynesian Phillips Curve (Model (6))

The second model considered is an expansion of the hybrid NKPC into an open economy hybrid NKPC in which intermediate goods are taken into account for marginal cost (Leith and Malley, 2003). In this model, real marginal cost depends on the domestic wage rate relative to the price of imported intermediate goods, the price of domestic intermediate goods relative to the price of imported intermediate goods (as the producers of final goods substitute domestic labour as an input with imported intermediate goods, according to the elasticity of their substitution $p$ ), and the output gap.

$\lambda$ is replaced with $\tilde{\lambda}$, and the additions to the NKPC are given by:

$$
\begin{gathered}
\tilde{\lambda} \equiv \frac{(1-\theta)(1-\theta \beta) \zeta_{t}}{\theta} \\
\zeta_{t} \equiv \frac{1}{\psi_{t} \mu-1} \\
\psi_{t}=\frac{1}{1-\alpha_{t}}
\end{gathered}
$$
Where $1-\alpha_{t}$ is the output share of labor and of imported intermediate goods, given by $1-\alpha=\mu \frac{s+i_{t}^{s}}{1+i_{t}^{s}}$, and
real marginal cost is given by

$$
\begin{aligned}
& m c_{t}^{r}=\hat{s}_{t}-(\psi-1)\left(\frac{i_{t}^{s}}{1+\left(1-\psi_{t}\right) i_{t}^{s}}\right) \hat{y}_{t}- \\
& -\left((1-\rho) \frac{i_{t}^{s}}{s+i_{t}^{s}}+\rho\left(\frac{i_{t}^{s}}{1+\left(1-\psi_{t}\right) i_{t}^{s}}\right) \frac{s_{t}}{s_{t}+i_{t}^{s}}\right)\left(\hat{w}_{t}-\hat{p}_{t}^{f}\right)+ \\
& +\left(\frac{i_{t}^{s}}{1+\left(1-\psi_{t}\right) i_{t}^{s}}\right)\left(\hat{p}_{t}^{d}-\hat{p}_{t}^{f}\right)
\end{aligned}
$$

where $i_{t}^{s}$ is the share of imported intermediate goods in output, $\hat{y}_{t}$ is the output gap, $\left(w_{t}-p_{t}^{f}\right)$ is the difference between the wage level and the price of foreign goods, and $\left(p_{t}^{d}-p_{t}^{f}\right)$ is the difference between the price of domestic goods and foreign goods. Since the steady-state labor share, s, and the steady-state share of intermediate inputs in GDP, $i^{\mathrm{s}}$, rise in our sample data, and following the treatment in Leith and Malley (2003), we allow this steady-state ratio to vary depending on the period. In all respects other than these, this specification is identical to the hybrid NKPC.

Having defined our theoretical framework, we now turn to the description of our data and methodology, followed by the presentation of our results.

\section{Methodology}

Our sample consists of 11 years of quarterly data for Croatia, beginning with 2000Q1 and ending with 2010Q4. Data are sourced from Eurostat, the Croatian National Bank and the Croatian Bureau of Statistics, and (for the price of Brent Crude oil) the U.S. Energy Information Administration. All time series data are seasonally adjusted, either by Eurostat or by the author and all variables that are hatted in a given equation are represented in the model as log-deviations from their steady state (for which we take the sample mean).

Inflation, $\pi_{t}$, is the GDP deflator. The difference between the price of energy and wages in equation (5), $\left(\hat{p}_{t}^{E}-\hat{w}_{t}\right)$, is the logarithmic difference of the price of Brent Crude oil on European markets (adjusted by the USD/HRK exchange rate for the period) minus nominal wages. The labour income share, $\hat{s}_{t}$, is the ratio 
of employee compensation to GDP, and the output gap, $\hat{y}_{t}$, is obtained by detrending real GDP with the Hodrick-Prescott filter. The difference between wages and domestic prices, $\left(\hat{w}_{t}-\hat{p}_{t}^{f}\right)$, is the logarithmic difference between nominal wages and the GDP deflator, and that between domestic and foreign prices $\left(p_{t}^{d}-p_{t}^{f}\right)$ is the logarithmic difference of the GDP deflator and the import deflator. The steady-state share of imported intermediate goods in GDP, $i_{t}^{s}$, consistently rises in our sample and is thus allowed to be time-varying, and since data on imports of intermediate goods are unavailable for Croatia, we follow the rule-of-thumb adjustment of Dabušinskas and Kulikov (2007) and assume that 50\% of imported goods are intermediates; we use this assumption since this is currently the sole precedent for such a rule-of-thumb adjustment in the literature, and Dabušinskas and Kulikov have achieved acceptable results. The rising steady-state value is obtained by applying the Hodrick-Prescott filter. Following relatively common choices in the literature (see, e.g., Mihailov, Rumler and Scharler, 2011; Dabušinskas and Kulikov, 2007), we set the discount factor $\beta$ to 0.98 , the markup $\mu$ to 1.2 , and the elasticity of substitution $\rho$ to 0.5 .

\section{Results}

Table 1 shows the resuls obtained for our three models: the hybrid NKPC, (model (3)), described by (3) and (4) with real marginal cost equal to the labor share of income, the energy-augmented hybrid NKPC, (model (5)), described by (3) and (4) with its real marginal cost given by (5), and the open economy hybrid NKPC, (model (6)), described by (3), (4) and (6) with its real marginal cost given by (7). All calculations were made according to the formulas, with the time series listed previously used where appropriate in the formulas.

Table 1

Empirical hybrid NKPC models for Croatia, 2000Q1 to 2010Q4

\begin{tabular}{|c|c|c|c|c|c|c|c|}
\hline & \multicolumn{2}{|c|}{$\begin{array}{l}\text { Structural } \\
\text { Parameters }\end{array}$} & \multicolumn{3}{|c|}{$\begin{array}{l}\text { Reduced-form } \\
\text { Parameters }\end{array}$} & \multicolumn{2}{|c|}{$\begin{array}{l}\text { Statistical } \\
\text { Tests }\end{array}$} \\
\hline & $\theta$ & $\omega$ & $\gamma_{b}$ & $\gamma_{f}$ & $\lambda$ & J-stat & $\begin{array}{l}\text { Cragg-Donald } \\
\text { F-stat }\end{array}$ \\
\hline $\begin{array}{l}\text { Model } \\
(3)\end{array}$ & $\begin{array}{c}0.9152 \\
(0.0077)\end{array}$ & $\begin{array}{c}0.3858 \\
(0.0006)\end{array}$ & $\begin{array}{c}0.4992 \\
(0.0050)\end{array}$ & $\begin{array}{c}0.5058 \\
(0.0047)\end{array}$ & $\begin{array}{c}0.0162 \\
(0.0042)\end{array}$ & 1.5108 & 8.8010 \\
\hline $\begin{array}{l}\text { Model } \\
(5)\end{array}$ & $\begin{array}{c}0.9090 \\
(0.0092)\end{array}$ & $\begin{array}{c}0.3878 \\
(0.0000)\end{array}$ & $\begin{array}{c}0.4911 \\
(0.0004)\end{array}$ & $\begin{array}{c}0.5487 \\
(0.0004)\end{array}$ & $\begin{array}{c}0.0434 \\
(0.0003)\end{array}$ & 1.0009 & 4.8044 \\
\hline $\begin{array}{l}\text { Model } \\
\text { (6) }\end{array}$ & $\begin{array}{c}0.9565 \\
(0.0059)\end{array}$ & $\begin{array}{c}0.3768 \\
(0.0005)\end{array}$ & $\begin{array}{c}0.4997 \\
(0.0048)\end{array}$ & $\begin{array}{c}0.5067 \\
(0.0046)\end{array}$ & $\begin{array}{c}0.0098 \\
(0.0030)\end{array}$ & 1.3364 & 7.9744 \\
\hline
\end{tabular}

Note: Standard errors are in parentheses. The instrument set includes both the current value and two lags of the marginal cost series; and four lags of the GDP deflator, of wage growth, of the output gap, and of the import deflator. The GMM estimation uses NeweyWest weighting matrices with a Bartlett kernel.

Source: Eurostat, Croatian National Bank, Croatian Bureau of Statistics, U.S. Energy Information Administration and author's calculations

The hybrid NKPC open economy model appears to have less explanatory power for inflation than either the conventional hybrid NKPC or the energy-augmented NKPC, since the value of $\lambda$, the coefficient of the marginal cost variable, is lower in the hybrid NKPC open economy model. It is possible to speculate extensively on the reasons for this, and we offer two possible explanations. Croatia's relatively low consumption (as a component of GDP) and low exports, and the fact that its service sector makes up approximately two thirds of its GDP, suggest that the cost of labor may make up much of marginal cost, and imported intermediate goods have a negligible influence. It is also possible that the rule of thumb we adopted due to insufficient data (the assumption that $50 \%$ of imported goods are intermediate inputs) may yield inaccurate results.

The $\lambda$ value of the energy-augmented NKPC (5) is, as increasingly predicted in the literature, higher than model (3), the conventional NKPC that takes into account for marginal cost only the labor share of income. Note that $\gamma_{f}$ is also higher in Model (5): this is in line with the theoretical prediction that, as marginal cost becomes a more significant driver of inflation, forward expectations will play a larger role and so the forward-looking component will have more influence.

The proportion of backward-looking firms, $\omega$, at close to $40 \%$ is near the range found in Krznar's (2011) 
comprehensive Croatian NKPC study. It is also, very roughly, in the range of values observed for the Baltic countries (Dabušinskas and Kulikov, 2007), and in line with Italy's but not that of other European G7 countries (Leith and Malley, 2003), all of which are to be reasonably expected. The percentage of firms that do not adjust prices in period $t$, given by $\theta$, is fairly high, but it is very close to the values in Krznar (2011); with such high $\theta$, the higher $\gamma_{b}$ compared to other cases in the literature does not come as a surprise (note that $\theta$ is lowest for (5), the energy-augmented model, where forward expectations are strongest).

The J-stat value shows the results of the test for overidentification of instruments. If there are more GMM moment conditions than there are parameters, the model is over-identified; Hansen's J-test is designed to test whether this is so. The scores for our models show that these models are not overidentified, and they are well within the range found in the literature.

The Cragg-Donald F-stat test assesses whether the models are susceptible to the problem of weak instruments. Although Model (5) has a lower score than the other two, all models are within the levels recommended in the literature, and thus they cannot be said to suffer from weak instruments.

\section{Discussion}

The richest area of NKPC research, without a doubt, is the study of proxies of real marginal cost. In the literature, a closed-economy model comprised of firms and households, with marginal cost being labour's share of income alone, has been predominantly used; this holds a number of drawbacks. It is inadequate for a small open economy, where including the cost of imported materials is necessary; it fails to take into account labor market frictions and materials prices; and in the interest of simplicity, it disregards the costs of capital investment.

Abstraction from reality is by definition necessary in a model, but the empirical results of models that rely only on labour's share of income are increasingly showing that it is vital to expand the proxy for real marginal cost. In this section, we discuss two recent efforts to construct an improved proxy, and consider their adaptation for a small open economy model that would be useful in Croatian inflation research.

\section{The NKPC with Labor Market Frictions}

Muto (2009) introduces to the NKPC labor market frictions in two forms: labor adjustment costs and real wage rigidity.

The model is given as follows: in period $t$, a firm faces a certain nominal adjustment cost associated with changing the number of its workers, defined as $\Omega$ w which is assumed to be a differentiable function of past and present labor input. This time dependence of $\Omega_{\dagger}$ means that the cost-minimization problem in this model is dynamic, and real marginal cost at period $t$ is calculated according to a formula incorporating the optimal number of workers in that period.

Under this model, discounted labor adjustment costs up to period t are necessary for empirical estimation. Muto (2009) deals with this by relying on data from the Bank of Japan's Short-Term Economic Survey of Enterprises in Japan (known as the TANKAN Survey), which asks employers whether they think their current number of workers is excessive and creates a so-called employment diffusion index that shows the net percentage of firms who consider their current number of workers excessive. Muto (2009) then defines the deviation of the current number of workers from the optimal amount as the labor gap, which is considered to imply the presence of labor adjustment costs (since the current number of workers would be equal to the optimal amount if labor adjustment costs were zero).

Using this elegant solution, Muto (2009) achieves a considerably better fit of the NKPC, and in his results real marginal cost is more statistically significant than in those studies where only labor's share of income is used as a proxy of real marginal cost; furthermore, he finds that labor market frictions are key in explaining the movements of real marginal cost. This would almost certainly have the same results for Croatia, increasing the value and the statistical significance of the $\lambda$ parameter, i.e. the real marginal cost parameter.

Adapting Muto's methodology to a small open economy such as Croatia would be invaluable, but in attempting to do so we face the obvious problem of gathering empirical data; to the best of the author's knowledge, no data such as that included in the TANKAN Survey is gathered for Croatia, so constructing a Croatian labor gap series is effectively impossible with existing data. Since Muto's results (2009) boast, in particular, greater statistical significance of the real marginal cost component - the goal of much recent NKPC research, and a property that makes the NKPC a much more useful tool of prediction - this is especially unfortunate.

It is possible that a statistical method might be devised to extract labor adjustment cost from currently available Croatian data, but this is beyond the scope of our study, and such an innovation could be the subject of a full study by itself. 


\section{The NKPC with Non-Labor Unit Costs}

In the model of Bratsiotis and Robinson (2009), the proxy for real marginal cost is total unit cost, which is made up of labor cost and of capital costs, net interest payments and production taxes; in this way, the net costs of investment are included in the calculation of real marginal cost.

Bratsiotis and Robinson develop extensive microfoundations on which they base their treatment of total unit costs. Their entire economic model is too extensive to be reproduced here, but for our purposes it is enough to state that, for the empirical estation, in addition to labor costs they use non-labor payments (non-farm) less corporate profits (non-farm), all of which are available from the US Bureau of Labor Statistics. Non-labor payments are defined as follows: consumption of fixed capital, net taxes on production and imports, net interest and miscellaneous payments (such as the cost of borrowing, and earned interest on financial assets) and business current transfer payments. This is added to labor cost to produce total unit cost, which is their proxy of real marginal cost.

This model finds that the real marginal cost component is much more statistically significant if total unit cost is used rather than labor cost alone; estimates of $\lambda$ relying on total unit cost estimates have a coefficient of approximately 0.05 , and those relying on labor unit costs have a coefficient of approximately 0.02. Also, it is important to note that using total unit costs produces a more accurate model in another way. Bratsiotis and Robinson's results (2009) imply fixed nominal contracts with a duration of 4 quarter or less; using only the cost of labor, the length would be at least 5-6 quarters, but firm-level surveys report 1.5 to 4 quarters.

It is clearly obvious that adapting this methodology to the case of Croatia would be extremely useful but, just as with Muto's model, we face the problem of inadequate data. To the best of the author's knowledge, no data comparable to that from the Bureau of Labor Statistics is collected for Croatia. As with Muto's model (2009), again, it is possible that useful results could be yielded from currently available data through a new statistical method, but that is properly a subject worthy of its own study.

\section{Conclusion}

In this paper, we study the movement of inflation in Croatia with a conventional hybrid NKPC, an energyaugmented hybrid NKPC, and an open economy hybrid NKPC, with the aim of examining the processes that drive inflation in Croatia and the aim of testing methods of more accurate estimation of real marginal cost. The results of our conventional hybrid NKPC model are in line with expectations based on the literature, the one exception being somewhat higher influence from backward-looking inflation than is commonly found, and the results of the energy-augmented NKPC seem promising for energy augmentation as an adjusted measure of real marginal cost. The performance of the open economy NKPC, meanwhile, is contrary to expectations and makes real marginal cost a less significant driver of inflation than the conventional model does. We offer suggestions for the reasons behind this in previous text.

This exploration is intended as a survey of interesting territory, and not (yet) that territory's meticulous charting. More work on the dynamics of inflation in Croatia, and on refinements to the NKPC, is highly needed. In addition to adapting the models mentioned earlier, new methodology would also be useful. Flaws in GMM are becoming increasingly discussed in the literature, and estimating the NKPC with Full Information Maximum Likelihood (FIML) appears to be a promising alternative that overcomes some of GMM's limitations. All these avenues of investigation are eminently worhy - and for Croatia, in particular, the nascent study of inflation in a New Keynesian framework (so far largely defined by Krznar's (2011) paper) needs the blooming of a thousand flowers.

\section{References}

1. Bratsiotis, G. J, Robinson, W. A. (2009), „Non-Labor Unit Costs, Marginal Costs and the New Keynesian Phillips Curve", Centre for Growth and Business Cycle Research Discussion Paper Series, University of Manchester, No. 123.

2. Calvo, Guillermo A. (1983), "Staggered Prices in a Utility Maximizing Framework", Journal of Monetary Economics, Vol. 12, No. 4, pp. 383-398.

3. Dabušinskas, A, Kulikov, D. (2007), „New Keynesian Phillips curve for Estonia, Latvia and Lithuania“, Bank of Estonia Working Paper Series, No. 7 (2007).

4. Galí, J. (2002), "New Perspectives On Monetary Policy, Inflation, and the Business Cycle“, Research Working Paper, No. 8767, National Bureau of Economic Research, Cambridge.

5. Galí, J, Gertler, M. (1999), "Inflation Dynamics: A Structural Econometric Analysis", Journal of Monetary Economics, Vol. 44, No. 2, pp. 195-222. 
6. Krznar, I. (2011), „Analiza kretanja domaće stope inflacije i Phillipsova krivulja“ [„An Analysis of the Domestic Inflation Rate Dynamics and the Phillips Curve"], Croatian National Bank Working Paper Series,No. I-031.

7. Leith, C, Malley, J. (2003), „Estimated Open Economy New Keynesian Phillips Curves for the G7“, CESifo Working Paper Series, No. 834.

8. Mazumder, S. (2010), "The New Keynesian Phillips Curve and the Cyclicality of Marginal Cost", Journal of Macroeconomics, Vol. 32, No. 3, pp. 747-765.

9. Mihailov, A, Rumler, F., Scharler, J. (2011), „The Small Open-Economy New Keynesian Phillips Curve: Empirical Evidence and Implied Inflation Dynamics", Open Economies Review, Vol. 22, No. 2, pp. $317-$ 337.

10. Muto, I. (2009), „Estimating a New Keynesian Phillips Curve with a Corrected Measure of Real Marginal Cost: Evidence in Japan", Economic Inquiry, Vol. 47, No. 4, pp. 667-684.

11. Rudd, J, Whelan, K. (2005), "Does Labor's Share Drive Inflation?", Journal of Money, Credit, and Bankin", Vol. 37, No. 2, pp. 297-312.

12. Rudd, J, Whelan, K., (2007), "Modelling Inflation Dynamics: A Critical Review of Recent Research", Journal of Money, Credit, and Banking, Vol. 39, No. s1, pp. 155-170.

13. Stock, J,Watson, M. (2008), „Phillips Curve Inflation Forecasts", Research Working Paper, No. 14322, National Bureau of Economic Research, Cambridge.

14. Wolman, A. (1999), "Sticky Prices, Marginal Cost, and the Behavior of Inflation", Federal Reserve Bank of Richmond Economic Quarterly, Vol. 85, No. 4, pp. 29-48.

\section{About the author}

Alan Domić is a student at the Faculty of Economics and Business, University of Zagreb. In recognition of his research work, he has received the Dean's Award from the Faculty and the Rector's Award from the University. As of 2012, he is engaged on a project at the Institute of Public Finance, and in the past he has collaborated on projects with firms such as Bloomberg Institute and A.T. Kearney. His research interests include econometric methodology, inflation assessment and measurement, and quasi fiscal operations. Author can be contacted at adomic@net.efzg.hr 